\title{
Overcoming the barriers of distance: Using mobile technology to facilitate moderation and best practice in initial teacher training.
}

\author{
Simon Leggatt, Department of Lifelong Learning Teacher Education, Secondary Education, PE and \\ Sport, University of Greenwich. London, $\mathrm{UK}^{1}$
}

\begin{abstract}
This case study describes the development process of a model using readily-available technology to facilitate collaboration, moderation and the dissemination of best practice in initial teacher training in the UK. Students, mentors, tutors and external examiners from a number of educational institutions in a UK, Higher Education led Lifelong Learning Sector partnership (LLS) participated. The study explored the extent to which using group video conferencing software and tablet computing had the potential to model best practice in giving feedback to students, in the setting of targets and in the joint observations of mentors and tutors based in separate institutions. A further area of investigation was the impact of the technology on the observation and moderation of teaching practice by external examiners. The study found that participants could identify a wide range of advantages of using the technology also some disadvantages. The impact of the study was measured qualitatively via the students' Professional Development Record (PDR). The challenges of undertaking a multi-site study requiring Wi-Fi connectivity and involving participants from several institutions are described. The introduction of Key Information Sets (KIS) related to employability creates an urgent need for HEIs to develop measures which enhance the employment prospects of all students.
\end{abstract}

This work was supported by the Higher Education Academy under Teaching Development Grant number TDG51

Key words: initial teacher training; feedback; technology, video conferencing, tablet computing, employability.

${ }^{1}$ Email: s.k.leggatt@gre.ac.uk 


\section{Introduction}

The widespread availability of new technologies presents educators with challenges and opportunities to deploy them in creative and productive ways (Kellner 2000). As well as meeting the needs of learners, technology is an essential tool for teachers and provides opportunities for their own professional development (Kirschner and Selinger 2003). An area in which technologies have been widely utilised internationally in higher education is in supporting the assessment of students on initial teacher training programmes (Jones et al. 2010; Lee and Wu 2006; Marsh et al. 2009, Sepp and Alam 2003). Marsh et al. (2010) note that one of the potential gains of video technology is the opportunity it offers initial teacher education to reflect through analysis of observed situations.

Reflection is an important learning outcome in initial teacher training because an effective teacher needs to be a reflective practitioner, capable of reflection and analysis of their own practice (Wellington and Ireson 2008) although, as Bishop and Denley (2007) observe, being asked to reflect is very different from being able to reflect. A key demand on UK teachers in the post-compulsory education arena is to complete their classroom-based training at a distance from their parent higher education institution (HEI) which consequently poses a challenge to HEIs with regard to the observation of teaching (Dyke et al. 2008).

Coupled with policy drivers recommending a more systematic assessment of trainees' performance in classroom settings in order to enhance the quality of teachers and teaching (OfSTED 2003, DfE 2010) there are good reasons for integrating readily available technologies in creative and productive ways. In addition, improvements in the assessment processes of teachers in training could promote both their attainment and employability. There is also a need to optimise the teaching resources due to the global recession (Loo 2013).

\section{Contextualisation}

Traditionally, teacher preparation institutions have considered their role to prepare teachers who know how to use technology (Flick and Bell 2000). However, there is evidence that there is far greater potential for the application of technology in initial teacher training. Gomez et al. (2008) argue that as well as helping students demonstrate their knowledge, a unique benefit of technology is that it can enable a wide range of new social arrangements, offering a way to connect students, and lecturers to the social fabric of communities of practice (Gomez et al. 2008; Putnam and Borko 2000).

A wide range of digital technologies is readily available to be used in the context of higher education including wikis (Su and Beaumont 2010), mobile tablets (Miller 2012; Sepp and Alam 2003) and the application of recording technologies to analyse teaching practice (Loo 2013; Zang et al. 2010). Applications like visualisation and dynamic modelling allow abstract concepts, for example feedback, to become tangible and dynamic for learners (Jackson et al. 2000; Swinglehust and Greenhalgh 2008).

Kinnear et al. (2002:18) found that the use of video conferencing in teacher training evaluated well with students noting that 'the real time experience added considerably to the vitality of the student experience'. In their review of the literature focusing on video analysis in teacher training, Rook and McDonald (2011) found that video based reflection, editing, and analysis can provide practitioners with the tools needed to examine and improve teaching practice. 


\section{Methodology}

When Dyke et al. (2008) investigated synchronous online assessment of trainee teachers, they found that online assessment was a viable alternative to face-to-face observation in circumstances where the on-line observer knew the teachers and the organisations in which they taught. Building on the work of Dyke et al. (2008), this paper describes a case study in which a range of video recordings were observed. These included: remote joint observations of practical teaching, remote feedback sessions and other uses of the technology, including self-evaluations of teaching using video recordings that students had made of their own lessons. The experience of participants was explored in order to evaluate the impact of the study.

A small scale, qualitative case study approach was utilised in order to capture and understand the experiences and perceptions of the sample group of subjects (Yin 2003). This was initially conceived as a mixed methods approach; using both qualitative and quantitative data collection methods, an approach more closely associated with the interpretive paradigm. However, a number of constraints emerged during the data collection phase; these were pressures upon the participants' time, geographical factors regarding the location of the participants and unanticipated technological hindrances. These latter meant that it was not possible to collect quantitative data from the online questionnaire or to analyse students' files. Although students, their tutors and external examiners participated as planned, mentor involvement was minimal, due to the hindrances identified.

\section{Participants}

A non-probability, purposive sampling method was used with the pool of possible participants chosen on the basis of what was already known about them and their specific context. The experience and context of participants was highly relevant as the study outcome was intended to inform development in the specific practice in which participants were involved. The participants were originally to be located at one of four of partner colleges in one 'cluster' of the University's teacher training partnership. However one of the colleges withdrew from the study after the proposal was submitted. This made it necessary to reduce the number of colleges involved from four to three. In total, nine students, four tutors and two external examiners participated.

Student participants were 'in-service' trainee teachers based in the colleges; either employees of the college where they were studying or attending the college as students from other parts of the sector. All nine participants were students on the Professional Graduate / Professional Certificate in Education (PGCE/PCE) for the Lifelong Learning Sector. All students on the programme identified their own mentor and were allocated a tutor by the college. The selection of mentors and tutors was random. Selection of external examiners was also random, as they were allocated on a geographical basis, determined by the location of the student participants following their selection.

All participants in this study were volunteers. Tutor and external examiner participation was secured as a result of the study lead making informal approaches to contacts known to have an interest in developing learning technologies. Student participation was secured following calls for expressions of interest made by tutors. All participants were free to withdraw at any time. The study was conducted in accordance with the University of Greenwich Revised Ethical Guidelines for Educational Research (2004) which included gaining informed consent from all participants.

\section{Methods}

The planned data collection method was that of a focus group with participants drawn randomly from the main sample group (Morgan 1993). However, the total number of participants was lower than anticipated because coordinating a focus group with geographically dispersed participants proved impractical. Therefore, an online questionnaire using a survey package was devised and sent to students, six of whom responded.

All tutors involved in the study were interviewed. Each interview was semi-structured, lasted approximately one hour and used the same set of core questions to guide the discussion. Discussions were recorded using a digital voice recorder or by capturing a video call session. The recordings were then transcribed verbatim. 


\section{Technology}

Four iPads were purchased for this study, together with three month data contracts to enable their use in situations where Wi-Fi was unavailable. However, it emerged that the limited bandwidth available via $3 \mathrm{G}$ was insufficient to meet the requirements of the video-calling application. Since one aim of the study was to be as cost-effective as possible, the decision was made to evaluate only those video calling applications that offered group calls without paying a subscription fee. Of key importance was that the chosen application could be installed on mobile devices as well as desktop and laptop devices and on both Mac and PC systems. Two applications were shortlisted: fring and oovoo. The decision to select oovoo was based on its ability to capture a group video call session in full for later viewing and transcription. This part of the study did not follow the study plan because it was not possible to place an order before the initial tranche of funding was released; in addition there were further delays in the internal procurement process resulting in a two month delay in all.

Once the hardware was successfully configured and the video calling application was installed and tested at the university, the study lead then undertook visits to all partner sites to train the tutors and external examiners in the use of the technologies. There were early indications of problems with securing a stable network connection to Wi-Fi in the colleges, although connecting wirelessly to the university network during testing had been successful.

A matrix of observations and participants was devised. However, the widely differing working patterns of all participating students and mentors across the four institutions posed a challenge to complete the observations as planned. 


\section{Findings}

The findings emerged as a result of comparing the experiences of the participants in the different contexts in which the technology was evaluated and then in the different ways in which it was used.

\section{Advantages}

The technology used had a number of benefits, both personal and professional identified by the study's participants. From a general perspective, the iPad had a distinct advantage over a fixed video recording set up. If the camera operator moved the iPad around the room, it was possible to zoom in on a small group discussion, a feature which challenges a fixed video camera. Viewing a feedback session was found to be more straightforward using an $\mathrm{iPad}$, too, and tutors commented that trainee teachers probably gained more from viewing and reviewing feedback practice than the actual lesson. Another of using the iPad was that footage did not need to be downloaded onto a computer in order to be viewed. Environmental and financial benefits of the iPad were also identified; with tutors identifying that they did not need to travel to different sites in order to observe students, one tutor commented:

"I think what it allowed the mentor - or indeed us, if the mentor was doing the observation - was to be off-site and still observe the session. Frankly, with increased pressure on time and availability, it just meant that you didn't need to physically drive for half an hour or an hour or whatever to be in another college - you can do it from here. You can watch what they are doing... So, if it saves me going to Vauxhall just once, that's good enough for me."

However, tutors did recognise that in order to maximise the benefit of the technology, it was necessary to carefully brief students in advance of the session. In addition, new ways would need to be established to manage the relevant paperwork, as one tutor explained:

"For example, lesson plans have been emailed to me in the past, so it does require some pre-preparation but I don't think that's a bad thing because it makes the student prepare properly - but it's just recognising that some things are going to work differently."

One external examiner identified the potential of the technology to promote quality assurance:

"Trainees abroad or in accessible places can still be observed and the feedback given to them by tutors or mentors can still be moderated by external examiners. The technology does have the potential to support moderation and the sharing of good practice across the network. It is a good idea for a distance learning programme and gets trainees into the habit of recording themselves on video and evaluating their teaching."

Opportunities to standardise practice and share good practice were also acknowledged by tutors in that the technology offered a convenient way to observe - and learn from - other tutors' feedback:

"We can observe other people's lessons from other centres and discuss those and see what is happening elsewhere. Now, I'm pretty much a course of one - or a team of one - I'm not getting any opportunities to standardise my practice in observations apart from once a year maybe, when I get a centre visit. So, the ability to watch other people's lessons and possibly the feedback that goes with all of that is actually a really good thing. "

Students responded favourably to the use of the iPad, because it meant that observations could be undertaken with minimal intrusion:

"Compared to other observations, it was less intrusive and students responded in a more normal manner during the lesson because of this".

Another student noted that:

"I was observed by using the technology; it didn't get in the way, the lesson carried on as normal".

It was also recognised that the features of more traditional observation processes could affect the classroom dynamics:

"If I was observed using the iPad, it would probably be an advantage in that there would not be an extra person in the classroom which can sometimes lead to students behaving in an unnatural way." 
All participants identified a wide ranging list of advantages of using the iPad and each group identified different advantages. As an observation tool, the iPad was seen as versatile, efficient, discreet, cost-effective and a means by which good practice could be discussed and shared. In addition observations using the iPad were seen as a method to support quality assurance.

\section{Disadvantages}

It was found that the quality of the built-in camera, type of lens and the quality of the microphone could affect the capability of the iPad. The fact that the camera was fixed and could therefore only see that which is visible from one position was seen as a as a potential disadvantage by some:

“... The only thing is the field of view. When we were observing that lesson which I thought was a good

experiment.... So things like camera angles are quite crucial because there could well be a bit you need to watch which is out of the camera shot..."

The iPad was less effective than a fixed video installation with more than one camera. In this respect, there is clearly a compromise between portability and function. It might be possible to use the iPad with a portable, wide angle lens and a higher quality microphone to address these limitations.

The study also experienced problems regarding consistent Wi-Fi connectivity. Participants noticed that the stability of the connection and the quality of the picture appeared to be dependent upon bandwidth capacity:

"The only thing I did notice was that if I was trying to use it as I do from the home base, as it were, and to try to get a multiple access to different people on the screen, that was problematic. It crashed, basically but I think that was to do with the quality of broadband rather than the app, I think. "

Another participant noted another disadvantage related to the skill of the device operator:

"There are some limitations to this because you cannot control the movement of the camera from the place that you are viewing. So it's fixed; you're at the mercy, really, of the person at the other end who might plonk it down in a particular position and just leave it. So, obviously your feedback is going to be highly restricted; it's not three-dimensional; you can't sort of manipulate the camera."

Confidence and familiarity with using technology - and also seeing oneself on camera - were aspects of the study that affected some participants:

“What's interesting is people's attitude towards videoing... I'm meeting people who haven't yet perhaps got their head around the idea of using video, to speak with someone in a live situation.... I think those sorts of skills are things which I would say have been developed from my point of view and it's actually good to be reminded that not everybody is comfortable with it."

"I think there are some people who are more tech savvy than others, so I can see some students going 'Yeah, that's great I can do that I've got an iPad; I've got a phone', and I can see others going 'No, don't want to do that'."

Lack of confidence was also an issue for tutors and a concern was raised regarding the wider implication of this skills deficit:

"I think to a large extent, as it seems to be a very effective way to record teaching practice. However, I think that it could be seen as a bit "Big Brother" by some less technologically inclined teachers."

This particular point was also highlighted by Dyke et al. (2008: 38) who noted: "Researchers are keenly aware that cameras in the classroom can be associated with notions of Big Brother and genuine anxieties exist about the proliferation of surveillance technology."

Related to their lack of confidence was the concern of some tutors regarding the lack of a 'Plan B' if the technology failed: 
"I think it's the technology issue, isn't it? You could arrange to debrief somebody or observe a lesson and if the technology is not working then you've lost that opportunity. So, although you might have more opportunity to do things, if it doesn't work, you aren't there with a pen to sort it out."

Tutors also commented upon the impact of interacting with students on an interpersonal level when using technology:

"I mean the difficulty is that although it's sort of face-to-face, it's not quite face-to-face. So you sometimes perhaps lose some of the subtlety of what somebody might be saying."

One tutor noted two potential obstacles when using technology in the classroom, data protection issues and the need to be skilled in recording video footage:

"I'm hoping that people won't get too hung up on the data protection stuff and just say 'Can I video a class?' and some people will just do it and not worry about it and nobody minds. I think it just depends on their personal confidence and also what they think they'll get out of it, but again they need to be making sure that what they are recording is from a sensible angle and a sensible place really."

One tutor highlighted the issue of how the 'evidence' of teacher performance might be misused:

"I came across a situation which would have been a really good one for using this which was a case I actually had where the student was in effect failing the teaching practice and I wanted to get a corpus of evidence of this so we could have a conference about it ...... but the problem there was that the curriculum manager was very negative to the idea of this stuff being videotaped because he thought it might get out into a public domain and he didn't want that to affect his kind of quality statements in respect of his own institution; it was a bit of an issue so I just stepped back from it and said 'OK we won't do that then'.'

The disadvantages of using technology that emerged from the findings were, like the advantages, wide-spread, ranging from personal concerns to wider, professional and even political concerns. 


\section{Impact}

The impact of the study emerges from its most significant finding in that technology provides the means to narrowcast live 'events' and share recordings. This technology offers individuals the opportunity to facilitate deep reflection on their practice; in addition, it offers the means to compare practice with that of others as supported by comments from tutors:
"Using it from the perspective of a practical example of how reflection can be carried out... because they can all do this, they can collect this and then actually use it for making analytical statements about 'what would you do differently?' 'What's happening there?'; 'Why is that happening?' and so on and so forth. There are one or two very powerful things in there, I think, both the bureaucratic process of getting it in...data protection etc. and also to begin talking about it as an everyday tool."
"It definitely does help students reflect because you can see first of all when they are actually looking at the stuff how they... and how we do it. When you do it for yourself and you look back on it and you say 'OK, well did I really say that?' 'Did I really do it in that particular way?' and it will aid things like the technique of questioning; can you, to what extent can you think in advance about the questions are going to work through and how can you develop that skill of immediately coming up with the appropriate question that will move the learning forward."

These views were also supported participating students:

"The feedback received was offered with my tutor being present, but the added bonus of the video helped to highlight good practice and possible areas for improvement. I found this useful because when you're teaching, it is not always possible to remember every aspect of the lesson and the video allowed me to see clearly the issues my tutor raised."

"The use of recordings for reflection purposes helped because it allowed me to review my own teaching style and both good and not so good practices. Also it helped me to remember issues at a later date."

"It was very helpful to see myself teaching, allowing me to critically analyse my performance and pick up on lots areas for improvement."

Some student participants were less confident that the study had made a difference to their target setting practice:

"Being on the teacher training course is a process of continual improvement and as this was part of that process I am unsure if this study had a major effect on developing targets. However it did offer the chance to review my own performance."

"Yes (it did support effective target setting practice), but probably in the same way as a traditional observation feedback session."

This study and the on-going use of technologies such as these, has the potential to develop confidence and valuable transferrable skills for employment as commented on by participating students:

"My confidence has grown; I enjoy learning about new technology and how it can help my lessons."

"After my involvement with this this project I would be happy to use it again, so I feel more confident."

"I would say that my confidence in using an iPad for recording of lessons/student feedback has greatly improved."

The participation of students also seems to have had a positive impact on how they plan to use technology with their own students and their approaches to teaching and learning:

"I am hoping to use the notion of video evidence in the future as part of the assessment evidence for Level 2 BTEC courses." 
"I now realise the students should be doing more talking than me!"

"It's important to always give feedback to learners, not just after assessments, but after every lesson and during lessons."

"By observing myself, I realised that I needed to re-assess the way I conduct practical demonstrations because I focused more on what I was making rather than focusing on the learners so this part became a little disjointed. On a positive note it was good to observe some of the good two-way interactions between myself and the learners."

\section{Implications for the Student Learning Experience}

As a tool for reflection, using these technologies has proven to be very beneficial. However, due to the unresolved technical issues, the extent to which the potential of the device could be fully realised was limited. This study has nonetheless provided the focus for further work. As the level of technical difficulty experienced on this study was not anticipated, any further development work must include a proportion of the costs for by technical expertise in order that immediate solutions could be found.

There are however some changes in practice which have resulted from the study which will continue beyond the period of funding. The participation of tutors has resulted in changes in the way they think about the technology and video generally as a tool for teaching and learning. There is also optimism that the current technical difficulties can be overcome. In terms of thinking about making use of this technology as an alternative to a 'face to face' observation, one tutor commented ( somewhat pragmatically):

"I don't think it's ideal because if you are actually in the room there are nuances you can pick up; you can see what happens rather than looking on film. You are aware of what's going down, as it were, and you can see, you know, people using phones on the tables and all sorts of things which a camera won't necessarily pick up. But I do think it's viable...Again with costs, constraints, times and so on I think it's almost probably inevitable once they get it all working properly."

"What I will be doing, with more confidence, is trying to build this gradually into the programmes as they develop in different ways. For example on the January induction, because of the weather, because we had to cancel the actual meeting which was on a Saturday, they all downloaded 'oovoo' and I said what we are going to do is do it online. More and more I'm going to be using it for individual tutorials; I'm already using Skype with individuals who have it... (This technology) ought to be a massive selling point of a distance programme."

"From my point of view, in terms of enabling them to set targets, yes, undoubtedly because once you've got the recording then you've got a corpus of evidence to go back on if you want to."

In relation to tutors' confidence with ICT:

"Right, it's increased I would say; I've definitely got more of a willingness to experiment than I might have had before. "

"I'm used to using Skype so you know, in terms of videoing stuff that's OK. It's made me realise I can use IT more; I've got another student who I've started because of where they work to Skype their lesson observations and that's actually working reasonably well."

For some participants, they clearly felt that this technology had applications beyond this study:

"When I started looking at this and other things we could do like film making, like embedding YouTube into PowerPoint, once we actually came up with a suite of things I thought this gave us another opportunity; another string to the bow. 'We could go in there with enough stuff to make it look like we knew what we were doing' was actually how I felt about it."

“Absolutely, and it's something that I'm going to be exploring in a separate project so I want to compare video recorded self-evaluations with the written traditional format. I suspect, I want to test it out, I suspect if people are comfortable talking to a camera they may be a little looser, they may sort of open up a little bit but we shall see. I think the sort of confines of the boxes on paper may be a little restrictive so I think there's some potential for that aspect to be explored." 


\section{Conclusions}

The iPad proved itself to be a powerful 'all in one' device for recording and reviewing the teacher's own performance, aiding the development of reflective capacity. The involvement in the study of both students and their tutors resulted in positive developments in the way both groups planned to approach future teaching and learning, with potential to exert a lasting effect on the student experience.

There was also wide agreement among participants that this technology could be a useful tool for quality assurance by allowing external examiners and other partners to observe teaching, feedback and moderation remotely.

Howwever, it appeared that the technology was not at a stage where sufficiently stable connectivity was available to facilitate truly synchronous 'mobile' joint observations and full sharing of good practice between partners.

Future studies must secure technical expertise regarding those connectivity issues that can be resolved. Once this has happened, it will then be possible to explore the full potential of this technology for all stakeholders.

(4.649 words)

\section{References}

Bishop, K. and P. Denley. 2007 Learning Science Teaching. Open University, Maidenhead

Department for Education. 2010. "The Importance of Teaching: The Schools White Paper"

https://www.gov.uk/government/uploads/system/uploads/attachment_data/file/175429/CM-7980.pdf

(accessed November 2013)

Dyke, M., A. Harding and S. Liddon. 2008. "How can online observation support the assessment and feedback, on classroom performance, to trainee teachers at distance in real time?" Journal of Further and Higher Education 32 (1) 37-46

Flick, L, and R. Bell. 2000. "Preparing tomorrow's science students to use technology: Guidelines for science educators" (Electronic version). Contemporary Issues in Technology and Teacher Education, 1 (1). Accessed November 2013, http://www.editlib.org/p/10803/

Gomez L.M, M. Gamoran Sherin, J. Griesdorn and L. Finn. 2008. "Creating Social Relationships: The role of technology in preservice teacher preparation." Journal of Teacher Education 59 (2) 117-131

Jackson, S, J. Krajcik and E. Soloway. 2000. "Model-it: A design retrospective". In M. Jacobson and R. Kozma (Eds) Advanced designs for the technologies of learning: Innovations in science and mathematics education (77-116). Mahwah, NJ: Lawrence Erlbaum.

Jones, A., E. Dean and C. Hui-Chan. 2010. "Comparison of teaching and learning outcomes between videolinked, web-based, and classroom tutorials: An innovative international study of profession education in physical therapy." Computers and Education, 54, 1193-1201

Kellner, D. 2000 "New Technologies/ New Literacies: reconstructing education for the new millennium" Teaching Education 11 (3) 245-265. 
Kinnear, H., E. McWilliams and L. Caul. 2002. "The use of interactive video in teaching teachers: An evaluation of a link with a primary school." British Journal of Education Technology 33 (1) 17-26.

Kirschner, P. and M. Selinger. 2003. "The State of Affairs of Teacher Education with Respect to Information and Communications Technology." Technology, Pedagogy and Education 12 (1) 5-17

Lee, G.C. and C. Wu. 2006. "Enhancing the teaching experience of pre-service teachers through the use of videos in web-based computer-mediated communication (CMC)." Innovations in Education and Teaching International, 43 (4) 369-380. Available online at: http://dx.doi.org/10.1080/14703290600973836

Loo, S, Y. 2013. "Professional development of teachers: using multimodality and reflective peer review approaches to analyse digitally recorded teaching practices." Teacher Development Published $4^{\text {th }}$ October 2013. Accessed November 2013, http://www.tandfonline.com/doi/abs/10.1080/13664530.2013.838602\#.Uo08DuLwV-0 .

Marsh, B., N. Mitchell and P. Adamczyk, P. 2009. "Interactive video technology: Enhancing professional learning in initial teacher education.” Computers \& Education 54 (3) 742 - 748

Miller, W. 2012. “iTeaching and Learning: Collegiate Instruction Incorporating Mobile tablets” in R. Miller, C. Meier, and H. Moorfield-Lang (Eds) Rethinking Referencing and Instruction with Tablets Library Technology Reports, November/December 2012 (48:8) http://alatechsource.metapress.com/content/W41833/ (Accessed November 2013)

Morgan D.L.1993 Successful Focus Groups. Sage, Newbury Park, CA.

Office for Standards in Education (Ofsted) 2003. The initial training of further education teachers. HMI Report 1762. London. Accessed November 2013, http://www.ofsted.gov.uk/resources/initial-training-offurther-education-teachers-2003

Rook, M. and S. McDonald. 2011. "Digital records of practice: A literature review of video analysis in teacher practice" http://innovation.ed.psu.edu/wpcontent/uploads/2011/12/KrauseInnovationStudio_SITE2012.pdf

$\mathrm{Su}, \mathrm{F}$ and C. Beaumont. 2010. "Evaluating the use of a wiki for collaborative learning." Innovations in Education and Teaching International, 47 (4) 417-431.

Swinglehurst, D., J, Russell. and T. Greenhalgh. 2007, "Peer observation of teaching in the online environment: an action research approach.” Journal of Computer Assisted Learning 24, 383-393

Putnam, R.T. and H. Borko. 2000. "What do new views of knowledge and thinking have to say about research on teacher learning?” Educational Researcher, 29 (1) 4 -15.

Yin, R. 2003. "Case Study Research: Design and Methods." (3 ${ }^{\text {rd }}$ edition), Applied Social Research Methods Volume 5. Sage Publications, California, U.S.A.

Zhang, M., M. Lundeberg, M. Koehler and Eberhardt, J. 2010. "Understanding affordances and challenges of three types of video for teacher professional development," Teaching and Teacher Education, 27 454462. Accessed November 2013, http://ictandenglish.webs.com/documents/Understanding\%20affordances $\% 20$ and $\% 20$ challenges $\% 20 \mathrm{of} \% 20 \mathrm{v}$ $\underline{\text { ideo.pdf }}$ 